\title{
Tuberculosis associates with both airflow obstruction and low lung function: BOLD results
}

\author{
André F.S. Amaral ${ }^{1}$, Sonia Coton ${ }^{1}$, Bernet Kato ${ }^{1}$, Wan C. Tan ${ }^{2}$, \\ Michael Studnicka ${ }^{3}$, Christer Janson ${ }^{4}$, Thorarinn Gislason ${ }^{5}$, David Mannino ${ }^{6}$, \\ Eric D. Bateman ${ }^{7}$, Sonia Buist ${ }^{8}$, Peter G.J. Burney ${ }^{1}$ and the BOLD Collaborative \\ Research Group ${ }^{9}$
}

\begin{abstract}
Affiliations: ${ }^{1}$ Respiratory Epidemiology, Occupational Medicine and Public Health, National Heart and Lung Institute, Imperial College, London, UK. ${ }^{2}$ University of British Columbia Heart Lung Innovation Center, Vancouver, BC, Canada. ${ }^{3}$ Department of Pulmonary Medicine, Paracelsus Medical University, Salzburg, Austria. ${ }^{4}$ Department of Medical Sciences: Respiratory Medicine and Allergology, Uppsala University, Uppsala, Sweden. ${ }^{5}$ Faculty of Medicine, University of Iceland and Landspitali University Hospital, Reykjavik, Iceland. ${ }^{6}$ Division of Pulmonary Critical Care and Sleep Medicine, University of Kentucky, Lexington, KY, USA. ${ }^{7}$ Department of Medicine, University of Cape Town, Cape Town, South Africa. ${ }^{8}$ Oregon Health \& Sciences University, Portland, OR, USA. ${ }^{9}$ For a list of the BOLD collaborators see the Acknowledgements.
\end{abstract}

Correspondence: André F.S. Amaral, Respiratory Epidemiology, Occupational Medicine and Public Health National Heart and Lung Institute, Imperial College London, Emmanuel Kaye Building, 1B Manresa Road, London, SW3 6LR, UK. E-mail: a.amaral囚imperial.ac.uk

ABSTRACT In small studies and cases series, a history of tuberculosis has been associated with both airflow obstruction, which is characteristic of chronic obstructive pulmonary disease, and restrictive patterns on spirometry. The objective of the present study was to assess the association between a history of tuberculosis and airflow obstruction and spirometric abnormalities in adults.

The study was performed in adults, aged 40 years and above, who took part in the multicentre, crosssectional, general population-based Burden of Obstructive Lung Disease study, and had provided acceptable post-bronchodilator spirometry measurements and information on a history of tuberculosis. The associations between a history of tuberculosis and airflow obstruction and spirometric restriction were assessed within each participating centre, and estimates combined using meta-analysis. These estimates were stratified by high- and low/middle-income countries, according to gross national income.

A self-reported history of tuberculosis was associated with airflow obstruction (adjusted odds ratio 2.51, 95\% CI 1.83-3.42) and spirometric restriction (adjusted odds ratio 2.13, 95\% CI 1.42-3.19).

A history of tuberculosis was associated with both airflow obstruction and spirometric restriction, and should be considered as a potentially important cause of obstructive disease and low lung function, particularly where tuberculosis is common.

@ERSpublications

Tuberculosis should be considered a potentially important risk factor for obstructive disease and low lung function http://ow.ly/Ns4vR

This article has supplementary material available from erj.ersjournals.com

Received: Dec 112014 | Accepted after revision: May 012015 | First published online: June 252015

Conflict of interest: Disclosures can be found alongside the online version of this article at erj.ersjournals.com

Copyright OERS 2015 


\section{Introduction}

In 2012, there were an estimated 8.6 million new cases of tuberculosis worldwide [1], with South-East Asia, Western Pacific Regions and Africa accounting for more than $75 \%$ of the toll. More than $30 \%$ of the world population may have latent tuberculosis but only $5-20 \%$ of them develop active tuberculosis at some point in their lifetime $[1,2]$. Those who survive it usually show post-treatment sequelae in the lung that may contribute to reduced quality of life and disability [3-5].

Airflow obstruction is characteristic of chronic obstructive pulmonary disease (COPD) and its main risk factor is tobacco smoking $[6,7]$. However, more than $20 \%$ of patients satisfying the criteria for COPD do not have a history of tobacco smoking $[8,9]$. Among other potential risk factors, a history of tuberculosis has been suggested by several studies as a strong predictor of chronic airflow obstruction that could explain COPD among nonsmokers [9-11]. With some exceptions, most of these studies were small $(\mathrm{n}<1000)$, not population-based (i.e. participants not randomly selected from general population) and limited to a single centre or country, and several used pre-bronchodilator instead of post-bronchodilator spirometric measurements [11].

Spirometric restriction is characteristic of restrictive lung diseases and has been reported as a consequence of tuberculosis since the late 1910s $[12,13]$. More recent epidemiological studies of South African miners and hospital-based cases have suggested that a history of tuberculosis and increasing number of events of this disease may lead to a deficit in lung function [14-18]. However, population data to support the association between a history of tuberculosis and spirometric restriction are lacking.

The aim of the present analysis was to assess the association of airflow obstruction and spirometric restriction with a history of tuberculosis in the large, international, population-based, Burden of Obstructive Lung Disease (BOLD) study.

\section{Methods}

\section{Participants}

The design and rationale for the BOLD study have been reported elsewhere [19]. Noninstitutionalised adults aged 40 years and older were sampled and invited to take part in the study. Sampling plans designed to randomly recruit a representative sample of the population at all study sites were used.

Support statement: The BOLD Study is funded by a grant from the Wellcome Trust (085790/Z/08/Z). The initial BOLD programme was funded in part by unrestricted educational grants to the Operations Center in Portland, OR, USA, from ALTANA, Aventis, AstraZeneca, Boehringer-Ingelheim, Chiesi, GlaxoSmithKline, Merck, Novartis, Pfizer, Schering-Plough, Sepracor and the University of Kentucky. Additional local support for BOLD sites was provided by: Boehringer Ingelheim China (Guangzhou, China); the Turkish Thoracic Society, Boehringer-Ingelheim and Pfizer (Adana, Turkey); Altana, Astra-Zeneca, Boehringer-Ingelheim, GlaxoSmithKline, Merck Sharpe and Dohme, Novartis, Salzburger Gebietskrankenkasse and the Salzburg Local Government (Salzburg, Austria); Research for International Tobacco Control, the International Development Research Centre, the South African Medical Research Council, the South African Thoracic Society, a GlaxoSmithKline Pulmonary Research Fellowship and the University of Cape Town Lung Institute (Cape Town, South Africa); Landspítali University Hospital Scientific Fund, GlaxoSmithKline Iceland and AstraZeneca Iceland (Reykjavik, Iceland); GlaxoSmithKline Pharmaceuticals, Polpharma, Ivax Pharma Poland, AstraZeneca Pharma Poland, ZF Altana Pharma, Pliva Kraków, Adamed, Novartis Poland, Linde Gaz Polska, Lek Polska, Tarchomińskie Zakłady Farmaceutyczne Polfa, Starostwo Proszowice, Skanska, Zasada, Agencja Mienia Wojskowego w Krakowie, Telekomunikacja Polska, Biernacki, Biogran, Amplus Bucki, Skrzydlewski, Sotwin and Agroplon (Krakow, Poland); Boehringer-Ingelheim, and Pfizer Germany (Hannover, Germany); the Norwegian Ministry of Health's Foundation for Clinical Research, and Haukeland University Hospital's Medical Research Foundation for Thoracic Medicine (Bergen, Norway); AstraZeneca, Boehringer-Ingelheim, Pfizer and GlaxoSmithKline (Vancouver, BC, Canada); Marty Driesler Cancer Project (Lexington, KY, USA); Altana, Boehringer Ingelheim (Phil), GlaxoSmithKline, Pfizer, Philippine College of Chest Physicians, Philippine College of Physicians and United Laboratories (Phil) (Manila, Philippines); Air Liquide Healthcare P/L, AstraZeneca P/L, Boehringer Ingelheim P/L, GlaxoSmithKline Australia P/L and Pfizer Australia P/L (Sydney, Australia); the Department of Health Policy Research Programme and Clement Clarke International (London, UK); Boehringer Ingelheim and Pfizer (Lisbon, Portugal); the Swedish Heart and Lung Foundation, The Swedish Association against Heart and Lung Diseases and GlaxoSmithKline (Uppsala, Sweden); GlaxoSmithKline, AstraZeneca and Eesti Teadusfond (Estonian Science Foundation) (Tartu, Estonia); AstraZeneca and CIRO HORN (Maastricht, The Netherlands); Sher-i-Kashmir Institute of Medical Sciences, Srinagar and J\&K (Srinagar, India); the Foundation for Environmental Medicine, Kasturba Hospital and the Volkart Foundation (Mumbai, India); Boehringer Ingelheim (Sousse, Tunisia); Boehringer Ingelheim (Fes, Morocco); Philippines College of Physicians, Philippines College of Chest Physicians, AstraZeneca, Boehringer Ingelheim, GlaxoSmithKline, Orient Euro Pharma, Otsuka Pharma and United laboratories Philippines (Nampicuan and Talugtug, Philippines); National Heart and Lung Institute, Imperial College, London (Pune, India); The Wellcome Trust, and the National Population Commission, Ile-Ife, Osun State, Nigeria (Ile-Ife, Nigeria); the Kyrgyz Thoracic Society (Bishkek, Kyrgyzstan); GlaxoSmithKline (Tirana, Albania); GSK, the Liverpool School of Tropical Medicine and the Malawi Liverpool Wellcome Trust (Blantyre, Malawi); The Saudi Thoracic Society and King Abdullah International Medical Research Center KAIMRC (Riyadh, Saudi Arabia); Salmawit Pharmaceuticals and Medical International Company Limited, and The Epidemiological Laboratory (Khartoum, Sudan); Boehringer Ingelheim (Annaba, Algeria); GlaxoSmithKline Pharmaceutical Sdn. Bhd. (Penang, Malaysia); and the BRAC Health Nutrition and Population Programme (Dhaka, Bangladesh). Funding information for this article has been deposited with FundRef. 
Of the 21962 participants who responded to the core questionnaire, 18669 had acceptable post-bronchodilator spirometry, and of these, 18664 answered a question on history of tuberculosis. Data were available from 27 sites, but Sydney (Australia), Mumbai and Srinagar (India), Penang (Malaysia), Ife (Nigeria), Bergen (Norway), Sousse (Tunisia) and Adana (Turkey), which each contained less than five participants with history of tuberculosis, were excluded; therefore, the present study population consists of 14050 participants from 19 sites.

The countries and sites represented in this analysis are: Tirana, Albania; Annaba, Algeria; Salzburg, Austria; Vancouver, BC, Canada; Guangzhou, China; London, UK; Tartu, Estonia; Hannover, Germany; Reykjavik, Iceland; Pune, India; Fes, Morocco; Maastricht, the Netherlands; Manila, Nampicuan and Talugtug, the Philippines; Krakow, Poland; Lisbon, Portugal; Cape Town, South Africa; Uppsala, Sweden; and Lexington, KY, USA. All sites received approval from their local ethics committee and participants provided written informed consent.

\section{History of tuberculosis}

Face-to-face interviews were conducted by trained and certified staff in the native language of the participant in order to collect information on respiratory symptoms, health status and exposure to risk factors. A history of tuberculosis was defined as a positive answer to the question "Has a doctor or other health care provider ever told you that you have tuberculosis?". Participants who were on treatment for tuberculosis at the time of the study were excluded from participation.

\section{Outcome measures}

Lung function, including forced expiratory volume in $1 \mathrm{~s}$ (FEV1) and forced vital capacity (FVC), was measured using the ndd EasyOne Spirometer (ndd Medizintechnik AG, Zurich, Switzerland) before and $15 \mathrm{~min}$ after administration of salbutamol $(200 \mu \mathrm{g})$ from a metered-dose inhaler through a spacer. The BOLD Pulmonary Function Reading Centre reviewed each spirogram and assigned them a quality score based on acceptability and reproducibility criteria from the American Thoracic Society (ATS) and European Respiratory Society (ERS) [20]. Spirometry technicians at BOLD sites were certified before data collection, received regular feedback on quality and were required to maintain a pre-specified quality standard.

Outcome measures were: 1) airflow obstruction, defined as a post-bronchodilator FEV1/FVC ratio below the lower limit of normal (LLN) for age and sex [21], based on reference equations for Caucasians derived from the third US National Health and Nutrition Examination Survey (NHANES) [22]; and 2) spirometric restriction, defined as a post-bronchodilator FVC below the LLN for height, age and sex, based on the same reference population.

\section{Statistical analysis}

To assess the association of airflow obstruction and spirometric restriction with history of tuberculosis, multivariable logistic regression models were fitted and adjusted for age (years), sex, body mass index (underweight: $<18.5 \mathrm{~kg} \cdot \mathrm{m}^{-2}$; normal: 18.5 to $<24 \mathrm{~kg} \cdot \mathrm{m}^{-2}$; overweight: 24 to $<30 \mathrm{~kg} \cdot \mathrm{m}^{-2}$; obese: $\geqslant 30 \mathrm{~kg} \cdot \mathrm{m}^{-2}$ ) and pack-years of smoking. Additional variables were considered as potential confounders: education (years of schooling completed), passive smoking (yes or no) and cumulative exposure to dust in the workplace (years). The association with a history of tuberculosis was estimated for each site using probability weights to allow for the sampling design at each site and then combined in a random-effects meta-analysis. The meta-analyses were stratified by gross national income, i.e. high- versus low/middle-income countries. The level of heterogeneity was summarised using the $\mathrm{I}^{2}$ statistic. We also regressed FEV1/FVC and FVC (litres) as continuous variables against the same independent variables as above. Sensitivity analyses were conducted excluding participants presenting with both airflow obstruction and spirometric restriction. In another set of sensitivity analyses, the association of a history of tuberculosis with airflow obstruction, spirometric restriction, $\mathrm{FEV} 1 / \mathrm{FVC}$ and $\mathrm{FVC}$ was assessed omitting all sites with a cooperation rate below 60\%. All analyses were conducted using Stata/IC V.12.1 (StataCorp LP, College Station, TX, USA).

\section{Results}

The characteristics of the 14050 participants with acceptable post-bronchodilator spirometry who responded to the core questionnaire and answered the question on history of tuberculosis are presented, by site, in table 1 . There were slightly more females than males and the overall age ranged from 52.3 to 59.6 years across sites. Cumulative smoking exposure, i.e. pack-years, and passive smoking varied widely across sites. The prevalence of a history of tuberculosis ( $0.7 \%$ in Tirana to $15.4 \%$ in Cape Town), airflow obstruction $(6.1 \%$ in Tartu and Pune to $19.5 \%$ in Cape Town) and spirometric restriction (8.5\% in Vancouver and Tartu to $66.1 \%$ in Pune) also varied across sites (tables 1 and 2). 
The unadjusted odds ratio (95\% CI) for the association between airflow obstruction and history of tuberculosis was 3.33 (2.54-4.37). Figure 1 shows adjusted odds ratios (aORs) and 95\% confidence intervals for this association, by gross national income group and site. Overall, the risk of airflow obstruction in people with a history of tuberculosis was more than twice as much as that of people without such a history (aOR 2.51, 95\% CI 1.83-3.42). This association was stronger in low/middle-income sites (aOR 3.11, 95\% CI 2.30-4.21) and showed no evidence of heterogeneity ( $\mathrm{I}^{2}=0 \%, \mathrm{p}=0.55$ ).

The unadjusted odds ratio $(95 \% \mathrm{CI})$ for the association between spirometric restriction and history of tuberculosis was 2.02 (1.42-2.86). Figure 2 shows adjusted odds ratios and 95\% confidence intervals by gross national income group and site for this association. The overall pooled aOR was 2.13 (95\% CI 1.42-3.19) and significant heterogeneity across sites was recorded $\left(\mathrm{I}^{2}=62.4 \%, \mathrm{p}<0.001\right)$. In high-income sites, there was no evidence of heterogeneity $\left(\mathrm{I}^{2}=0 \%, \mathrm{p}=0.72\right)$ but the risk was low and not significant (aOR $1.43,95 \%$ CI 0.93-2.18). In low-income countries, although the risk was higher and significant (aOR 3.19, 95\% CI $1.70-5.99)$ there was a marked and unexplained heterogeneity in the risk estimates $\left(\mathrm{I}^{2}=79.1 \%, \mathrm{p}<0.001\right)$.

In both figures 1 and 2, odds ratios are adjusted for age, sex, body mass index and pack-years. Adjustment for education, passive smoking and cumulative exposure to dust in the workplace did not materially change the estimates for the effect of tuberculosis. Krakow was excluded from the analyses due to an insufficient number of participants with both a history of tuberculosis and either airflow obstruction $(n=0)$ or spirometric restriction $(\mathrm{n}=2)$.

A history of tuberculosis was also associated with both decreased FEV1/FVC $(\beta=-3.43,95 \% \mathrm{CI}-5.05--1.80$; $\left.\mathrm{I}^{2}=65.3 \%, \mathrm{p}<0.001\right)$ and decreased FVC $\left(\beta=-0.15,95 \%\right.$ CI $\left.-0.23--0.06 ; \mathrm{I}^{2}=48.6 \%, \mathrm{p}=0.01\right)$ (supplementary figures 1 and 2).

Sensitivity analyses, excluding 482 participants who had both $\mathrm{FEV} 1 / \mathrm{FVC}<\mathrm{LLN}$ and $\mathrm{FVC}<\mathrm{LLN}$, showed that the magnitude of the effects of tuberculosis reduced slightly but remained statistically significant (aOR for airflow obstruction 2.13, 95\% CI 1.40-3.23; aOR for spirometric restriction $2.11,95 \%$ CI 1.31-3.38), suggesting that these effects are largely independent of each other.

The omission of sites with a cooperation rate below $60 \%$ did not materially change the results (supplementary figures 3-6).

\section{Discussion}

In this population-based study of adults aged 40 years and over, a history of tuberculosis was associated with increased risk of airflow obstruction. A history of tuberculosis was also associated with spirometric restriction but mainly in sites in low/middle-income countries.

The strengths of the present study are: 1) its large population-based sample and the inclusion of a great number of sites; 2) the use of a standardised questionnaire for collection of data on risk factors and protocol for spirometry across sites; and 3) the use of post- instead of pre-bronchodilator spirometric measurements. The most convincing effect relates to obstruction in low/middle income countries where the odds ratio was high (OR 3.11) and the results were consistent between sites $\left(\mathrm{I}^{2}=0 \%\right)$.

Our study also has some limitations. One is its cross-sectional nature, which impedes us from drawing conclusions in terms of temporality and makes us consider the possibility of reverse causation. Tuberculosis is more common in people with some restrictive diseases such as silicosis, but these are relatively very rare. Tuberculosis may also be reactivated in those who take corticosteroids, particularly inhaled corticosteroid treatment recommended in chronic airway disease. However, their use is rare in this population and even rarer in the low/middle-income countries, where the association between tuberculosis and airflow obstruction is most pronounced. At some sites, response rates were lower than desirable but when we omitted all sites with a cooperation rate below $60 \%$, the results did not materially change. Another limitation is the use of data on a self-reported history of tuberculosis, which may suffer from under-reporting due to stigmatisation of the diagnosis. However, differential under-reporting due to stigmatisation between people with and without airflow obstruction or spirometric restriction seems unlikely. It is also possible that several participants have suffered from tuberculosis and healed without any treatment, and thus, tuberculosis infection may be underestimated. However, in a study in China, the magnitude of the association of airflow obstruction with tuberculosis was similar between self-reports and radiological confirmation [23]. According to ATS/ERS [24], pulmonary restriction is defined by a total lung capacity (TLC) less than the fifth percentile of the predicted value. This implies measuring TLC by plethysmography or helium dilution, which is unrealistic in large-scale epidemiological studies such as this, especially at centres in low/middle-income countries. We are mindful that our choice of FVC as a surrogate of TLC may lead to false-positive findings in those with increased residual volumes but outside the clinical environment, the prevalence of this is very low. We are also aware that the use of the 
TABLE 1 Characteristics of participants from 19 sites of the BOLD study with good quality spirometry and data on history of tuberculosis (at least five cases) Tirana, Annaba, Salzburg, Vancouver, Guangzhou, London, Tartu, Hannover, Reykjavik, Pune, India Fes, Maastricht, the Manila, the Nampicuan Krakow, Lisbon, Cape Town, Uppsala, Lexington,
UK

\begin{tabular}{|c|c|c|c|c|c|c|c|c|c|c|c|c|c|c|c|c|c|c|c|}
\hline Subjects $n$ & 939 & 890 & 1253 & 827 & 461 & 675 & 613 & 680 & 757 & 845 & 768 & 590 & 892 & 722 & 526 & 711 & 846 & 547 & 508 \\
\hline Age years & $55.4 \pm 11.7$ & $53.5 \pm 10.9$ & $59.2 \pm 12.2$ & $56.8 \pm 12.7$ & $54.0 \pm 10.6$ & $58.0 \pm 12.4$ & $59.6 \pm 12.2$ & $57.7 \pm 11.1$ & $57.0 \pm 12.0$ & $52.3 \pm 10.0$ & $54.2 \pm 11.9$ & $58.5 \pm 12.0$ & $52.7 \pm 11.1$ & $54.2 \pm 10.6$ & $56.2 \pm 11.8$ & $58.5 \pm 12.0$ & $53.5 \pm 10.5$ & $58.9 \pm 11.4$ & $57.0 \pm 11.6$ \\
\hline Males \% & 48.9 & 49.9 & 46.1 & 47.3 & 52.0 & 46.2 & 39.1 & 45.4 & 51.3 & 59.8 & 52.2 & 46.8 & 47.5 & 49.4 & 49.6 & 45.3 & 43.8 & 47.1 & 46.4 \\
\hline $\mathrm{BMI}^{*} \mathrm{~kg} \cdot \mathrm{m}^{-2}$ & $28.0 \pm 4.6$ & $28.2 \pm 5.6$ & $26.4 \pm 4.3$ & $26.7 \pm 5.1$ & $23.3 \pm 3.2$ & $27.3 \pm 5.2$ & $28.4 \pm 5.4$ & $27.1 \pm 4.6$ & $27.9 \pm 5.0$ & $22.1 \pm 3.9$ & $27.5 \pm 5.2$ & $27.5 \pm 4.6$ & $24.4 \pm 4.7$ & $21.6 \pm 4.1$ & $27.8 \pm 4.7$ & $27.9 \pm 4.7$ & $27.5 \pm 7.3$ & $26.9 \pm 4.4$ & $30.6 \pm 6.5$ \\
\hline $\begin{array}{l}\text { Smoking history" } \\
\text { pack-years }\end{array}$ & $11.5 \pm 19.3$ & $10.4 \pm 18.3$ & $12.7 \pm 20.7$ & $12.1 \pm 21.4$ & $11.8 \pm 17.7$ & $17.5 \pm 27.4$ & $7.4 \pm 13.0$ & $14.6 \pm 20.4$ & $12.9 \pm 24.9$ & $0.7 \pm 3.6$ & $6.6 \pm 14.9$ & $14.5 \pm 19.0$ & $10.6 \pm 18.6$ & $12.9 \pm 18.4$ & $15.8 \pm 25.5$ & $13.1 \pm 25.0$ & $11.9 \pm 16.1$ & $10.4 \pm 16.2$ & $24.4 \pm 34.7$ \\
\hline Passive smoking \% & 37.4 & 10.9 & 21.8 & 5.7 & 23.6 & 16.6 & 15.6 & 18.6 & 16.8 & 11.1 & 11.4 & 17.7 & 48.8 & 47.3 & 39.3 & 18.7 & 50.6 & 5.8 & 29.6 \\
\hline Education ${ }^{+}$years & $10.0 \pm 4.6$ & $7.7 \pm 5.4$ & $9.8 \pm 2.2$ & $15.4 \pm 3.4$ & $8.4 \pm 3.9$ & $13.6 \pm 3.6$ & $13.5 \pm 3.8$ & $10.3 \pm 2.2$ & $13.2 \pm 4.4$ & $4.3 \pm 4.3$ & $4.2 \pm 5.3$ & $14.9 \pm 5.1$ & $9.4 \pm 3.6$ & $7.8 \pm 3.6$ & $10.4 \pm 3.4$ & $8.5 \pm 4.9$ & $7.8 \pm 3.3$ & $12.8 \pm 4.0$ & $12.8 \pm 3.3$ \\
\hline $\begin{array}{l}\text { Cumulative exposure } \\
\text { to dust in } \\
\text { workplace }^{\text {s }} \text { years }\end{array}$ & $15.0 \pm 14.1$ & $5.6 \pm 10.3$ & $5.2 \pm 11.7$ & $3.1 \pm 7.5$ & $6.9 \pm 11.6$ & $4.0 \pm 9.7$ & $5.0 \pm 10.1$ & $3.3 \pm 8.7$ & $4.2 \pm 9.6$ & $1.8 \pm 5.5$ & $8.5 \pm 12.8$ & $3.3 \pm 8.8$ & $7.1 \pm 10.8$ & $6.1 \pm 11.8$ & $10.5 \pm 13.4$ & $10.6 \pm 14.3$ & $6.8 \pm 10.3$ & $5.5 \pm 11.3$ & $8.3 \pm 12.1$ \\
\hline PB-FEV $L_{1} \cdot \mathrm{s}^{-1}$ & $2.8 \pm 0.8$ & $2.7 \pm 0.8$ & $2.9 \pm 0.9$ & $3.0 \pm 0.9$ & $2.4 \pm 0.7$ & $2.7 \pm 0.9$ & $2.9 \pm 0.9$ & $3.0 \pm 0.8$ & $3.0 \pm 0.9$ & $2.2 \pm 0.6$ & $2.7 \pm 0.7$ & $2.9 \pm 0.9$ & $2.1 \pm 0.6$ & $2.1 \pm 0.7$ & $2.9 \pm 0.9$ & $2.7 \pm 0.9$ & $2.3 \pm 0.7$ & $3.0 \pm 0.9$ & $2.7 \pm 0.9$ \\
\hline PB-FVC L & $3.5 \pm 0.9$ & $3.4 \pm 0.9$ & $3.9 \pm 1.0$ & $4.0 \pm 1.1$ & $3.1 \pm 0.8$ & $3.6 \pm 1.1$ & $3.8 \pm 1.1$ & $3.9 \pm 1.0$ & $4.0 \pm 1.0$ & $2.7 \pm 0.7$ & $3.4 \pm 0.9$ & $3.8 \pm 1.1$ & $2.6 \pm 0.7$ & $2.7 \pm 0.8$ & $3.8 \pm 1.0$ & $3.4 \pm 1.1$ & $3.0 \pm 0.9$ & $3.9 \pm 1.1$ & $3.5 \pm 1.1$ \\
\hline $\begin{array}{l}\text { History of } \\
\text { tuberculosis \% }\end{array}$ & 0.7 & 2.2 & 2.9 & 3.2 & 3.5 & 2.1 & 7.0 & 3.6 & 4.0 & 0.9 & 1.4 & 1.4 & 10.8 & 3.6 & 2.8 & 4.5 & 15.4 & 1.1 & 1.9 \\
\hline
\end{tabular}

Data are presented as mean \pm SD unless otherwise stated. BOLD: Burden of Obstructive Lung Disease; BMI: body mass index; education: years of schooling complete; PB: post-bronchodilator; FEV1: forced expiratory volume in $1 \mathrm{~s}$; FVC: forced vital capacity. "\# : missing data for three subjects in Krakow, two in Cape Town and one in Lexington; " Manila, three in Nampicuan and Talugtug, three in Krakow, two in Vancouver, two in Cape Town, two in Maasstricht, one in Reykjavik, one in Fes and one in Uppsala; ${ }^{+}$: missing data for seven subjects in Nampicuan and Talugtug, five in London, one in Tartu, one in Fes, one in Lisbon and one in Cape Town; ${ }^{\S}$ : missing data for four subjects in Maastricht.

TABLE 2 Estimated population prevalence of airflow obstruction and spirometric restriction in 19 sites of the BOLD study with good quality spirometry and data on history of tuberculosis (at least five cases)

Tirana, Annaba, Salzburg, Vancouver, Guangzhou, London, Tartu, Hannover, Reykjavik, Pune, Fes, Maastricht, Manila, Nampicuan Krakow, Lisbon, Cape Uppsala, Lexington, Albania Algeria Austria BC, Canada China UK Estonia Germany Iceland India Morocco the the and Talugtug, Poland Portugal Town, Sweden KY, USA

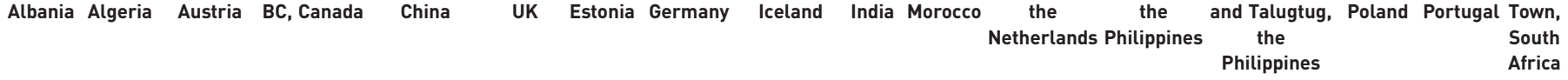

\begin{tabular}{|c|c|c|c|c|c|c|c|c|c|c|c|c|c|c|c|c|c|c|c|}
\hline Subjects $\mathrm{n}$ & 939 & 890 & 1253 & 827 & 461 & 675 & 613 & 680 & 757 & 845 & 768 & 590 & 892 & 722 & 526 & 711 & 846 & 547 & 508 \\
\hline Airflow obstruction \% & 8.9 & 6.4 & 17.4 & 13.5 & 7.6 & 17.6 & 6.1 & 8.2 & 11.3 & 6.1 & 8.9 & 18.8 & 9.4 & 15.2 & 13.5 & 8.3 & 19.5 & 9.6 & 14.4 \\
\hline Spirometric restriction \% & 16.1 & 26.5 & 9.3 & 8.5 & 29.9 & 17.8 & 8.5 & 9.0 & 12.5 & 66.1 & 19.3 & 10.1 & 62.7 & 56.7 & 10.1 & 10.7 & 46.7 & 10.2 & 26.2 \\
\hline Response rate $\%$ & 82.3 & 94.6 & 65.0 & 26.0 & 87.0 & 17.0 & 49.0 & 59.0 & 81.0 & 97.0 & 98.0 & 48.0 & 58.0 & 85.5 & 78.0 & 10.0 & 63.0 & 61.0 & 14.0 \\
\hline Cooperation rate ${ }^{\pi} \%$ & 84.0 & 94.6 & 67.0 & 51.0 & 87.0 & 37.0 & 70.0 & 61.0 & 84.0 & 97.0 & 98.0 & 55.0 & 58.0 & 86.2 & 79.0 & 27.0 & 68.0 & 63.0 & 27.0 \\
\hline
\end{tabular}

Airflow obstruction was defined as a forced expiratory volume in $1 \mathrm{~s} /$ forced vital capacity (FVC) ratio below the lower limit of normal (LLN). Spirometric restriction was defined as an FVC below the LLN. BOLD: Burden of Obstructive Lung Disease. \#: denominator comprises people of unknown eligibility status who could not be contacted; only known participants considered ineligible were excluded. "?: denominator comprises only participants who were contacted and eligible. 


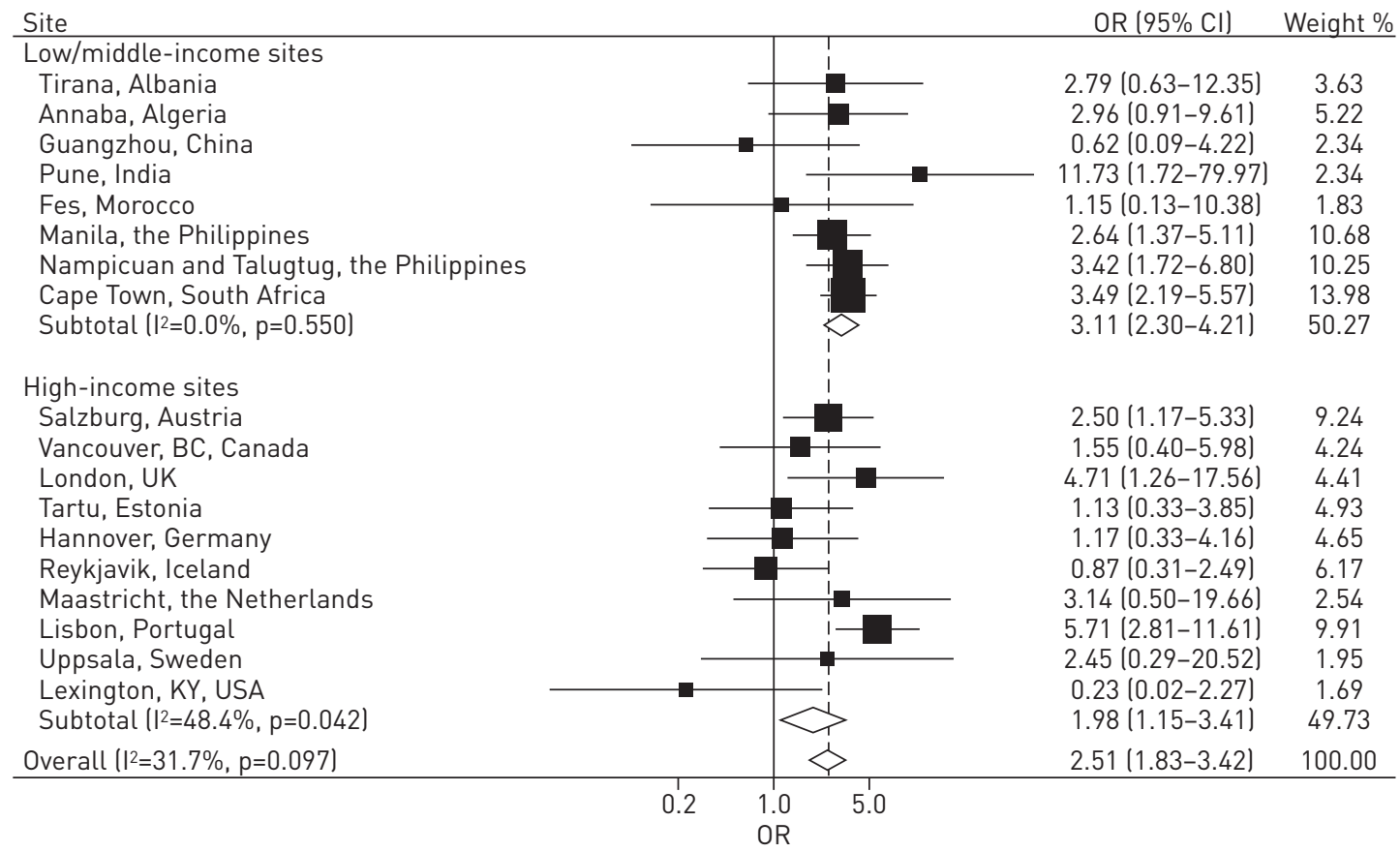

FIGURE 1 Odds ratios of airflow obstruction for a history of tuberculosis, by gross national income group (low/middle versus high) and site. All models were adjusted for age, sex, body mass index and pack-years of smoking.

NHANES reference equations in our spirometry measurements may overemphasise lung function abnormality at some study sites but the effect of this is unlikely to be differential as the analyses were done within each site (the sites are fairly ethnically homogeneous) and only then were meta-analysed. In addition, the results from the binary outcomes (FEV1/FVC $<\mathrm{LLN}$ and $\mathrm{FVC}<\mathrm{LLN}$ ) are supported by those of the continuous outcomes (FEV1/FVC and FVC), which are independent of reference equations.

\begin{tabular}{|c|c|c|}
\hline \multirow{2}{*}{\multicolumn{3}{|c|}{$\begin{array}{l}\text { Site } \\
\text { Low/middle-income sites }\end{array}$}} \\
\hline & & \\
\hline Tirana, Albania & $7.14(4.10-12.45)$ & 9.00 \\
\hline Annaba, Algeria & $4.06(1.41-11.69)$ & 6.25 \\
\hline Guangzhou, China & $1.91(0.64-5.71)$ & 6.05 \\
\hline Pune, India & $2.17(0.22-21.20)$ & 2.46 \\
\hline Fes, Morocco & $60.15(9.64-375.43)$ & 3.39 \\
\hline Manila, the Philippines & $2.14(1.17-3.89)$ & 8.75 \\
\hline Nampicuan and Talugtug, the Philippines & $1.68(0.83-3.39)$ & 8.16 \\
\hline Cape Town, South Africa & $1.47(0.95-2.27)$ & 9.62 \\
\hline Subtotal $\left(\left.\right|^{2}=79.1 \%, p<0.001\right)$ & $3.19(1.70-5.99)$ & 53.67 \\
\hline \multicolumn{3}{|l|}{ High-income sites } \\
\hline Salzburg, Austria & $1.12(0.40-3.15)$ & 6.35 \\
\hline Vancouver, BC, Canada & $1.54(0.37-6.36)$ & 4.67 \\
\hline London, UK & $0.75(0.14-4.18)$ & 3.70 \\
\hline Tartu, Estonia & $2.39(0.89-6.43)$ & 6.59 \\
\hline Hannover, Germany & $0.49(0.10-2.27)$ & 4.23 \\
\hline Reykjavik, Iceland & $1.33(0.49-3.60)$ & 6.57 \\
\hline Maastricht, the Netherlands & $1.10(0.12-10.33)$ & 2.53 \\
\hline Lisbon, Portugal & $4.36(1.05-18.17)$ & 4.64 \\
\hline Uppsala, Sweden & $1.16(0.14-9.58)$ & 2.77 \\
\hline Lexington, KY, USA & $1.27(0.27-5.86)$ & 4.26 \\
\hline Subtotal $\left(\left.\right|^{2}=0.0 \%, p=0.723\right)$ & $1.43(0.93-2.18)$ & 46.33 \\
\hline Overall $\left(I^{2}=62.4 \%, p=0.001\right)$ & $2.13(1.42-3.19)$ & 100.00 \\
\hline
\end{tabular}

FIGURE 2 Odds ratios of spirometric restriction for a history of tuberculosis, by gross national income group (low/middle versus high) and site. All models were adjusted for age, sex, body mass index, and pack-years of smoking. 
Our findings add to existing knowledge and support the majority of previous smaller studies that have reported an association between airflow obstruction and a history of tuberculosis $[10,11,25]$. We also confirm findings from the few occupational and small hospital-based studies that have observed a decline in lung function associated with both history of and radiographically confirmed tuberculosis [14-18].

Although it is widely accepted that tuberculosis, and the healing process the lung undergoes during and after treatment, can cause scarring that leads to loss of parenchymal tissue and restrictive spirometry, it is not clear what mechanisms explain airflow obstruction associated with tuberculosis. The finding that tuberculosis is associated with airflow obstruction, and not only with spirometric restriction, suggests that this is not solely the result of parenchymal scarring. One possibility is that this is caused by bronchiectasis and bronchial stenosis, which can occur as a result of tuberculosis [26]. Another possibility is that this is caused by a dysregulation of macrophages arising from latent intracellular infection [27]. Macrophages in the lung act primarily to kill bacteria or to facilitate wound healing and resolution [28], and it is widely accepted that they play a central role in the remodelling that causes chronic airflow obstruction. It is possible that latent mycobacteria in lung macrophages could lead to maintenance of inflammation in the lung and more aggressive remodelling of the airways [28, 29].

In summary, a history of tuberculosis was associated with both airflow obstruction and spirometric restriction. Nevertheless, large longitudinal studies with post-bronchodilator spirometry are recommended to confirm or refute these findings. With the continuing spread of tuberculosis in developing countries, an increasing incidence of multidrug-resistant disease and an ageing world population, it is important to improve our understanding of the mechanisms that link tuberculosis to airflow obstruction and COPD, and to devise effective strategies to limit this problem.

\section{Acknowledgements}

The BOLD collaborators were: NanShan Zhong (principal investigator), Shengming Liu, Jiachun Lu, Pixin Ran, Dali Wang, Jingping Zheng and Yumin Zhou (Guangzhou Institute of Respiratory Diseases, Guangzhou Medical College, Guangzhou, China); Ali Kocabaş (principal investigator), Attila Hancioglu, Ismail Hanta, Sedat Kuleci, Ahmet Sinan Turkyilmaz, Sema Umut and Turgay Unalan (Cukurova University School of Medicine, Department of Chest Diseases, Adana, Turkey); Michael Studnicka (principal investigator), Torkil Dawes, Bernd Lamprecht and Lea Schirhofer (Paracelsus Medical University, Department of Pulmonary Medicine, Salzburg Austria); Eric Bateman (principal investigator), Anamika Jithoo (principal investigator), Desiree Adams, Edward Barnes, Jasper Freeman, Anton Hayes, Sipho Hlengwa, Christine Johannisen, Mariana Koopman, Innocentia Louw, Ina Ludick, Alta Olckers, Johanna Ryck and Janita Storbeck, (University of Cape Town Lung Institute, Cape Town, South Africa); Thorarinn Gislason (principal investigator), Bryndis Benedikdtsdottir, Kristin Jörundsdottir, Lovisa Gudmundsdottir, Sigrun Gudmundsdottir and Gunnar Gundmundsson (Landspitali University Hospital, Department of Allergy, Respiratory Medicine and Sleep, Reykjavik, Iceland); Ewa Nizankowska-Mogilnicka (principal investigator), Jakub Frey, Rafal Harat, Filip Mejza, Pawel Nastalek, Andrzej Pajak, Wojciech Skucha, Andrzej Szczeklik and Magda Twardowska, (Division of Pulmonary Diseases, Department of Medicine, Jagiellonian University School of Medicine, Krakow, Poland); Tobias Welte (principal investigator), Isabelle Bodemann, Henning Geldmacher and Alexandra Schweda-Linow (Hannover Medical School, Hannover, Germany); Amund Gulsvik (principal investigator), Tina Endresen and Lene Svendsen (Department of Thoracic Medicine, Institute of Medicine, University of Bergen, Bergen, Norway); Wan C. Tan (principal investigator) and Wen Wang (iCapture Center for Cardiovascular and Pulmonary Research, University of British Columbia, Vancouver, BC, Canada); David M. Mannino (principal investigator), John Cain, Rebecca Copeland, Dana Hazen and Jennifer Methvin, (University of Kentucky, Lexington, KY, USA); Renato B. Dantes (principal investigator), Lourdes Amarillo, Lakan U. Berratio, Lenora C. Fernandez, Norberto A. Francisco, Gerard S. Garcia, Teresita S. de Guia, Luisito F. Idolor, Sullian S. Naval, Thessa Reyes, Camilo C. Roa Jr, Maria Flordeliza Sanchez and Leander P. Simpao (Philippine College of Chest Physicians, Manila, Philippines); Christine Jenkins (principal investigator), Guy Marks (principal investigator), Tessa Bird, Paola Espinel, Kate Hardaker and Brett Toelle (Woolcock Institute of Medical Research, Sydney, Australia); Peter G.J. Burney (principal investigator), Caron Amor, James Potts, Michael Tumilty and Fiona McLean (National Heart and Lung Institute, Imperial College, London, UK); Emile F.M. Wouters and Geertjan Wesseling (Maastricht University Medical Center, Maastricht, the Netherlands); Cristina Bárbara (principal investigator), Fátima Rodrigues, Hermínia Dias, João Cardoso, João Almeida, Maria João Matos, Paula Simão, Moutinho Santos and Reis Ferreira (The Portuguese Society of Pneumology, Lisbon, Portugal); Christer Janson (principal investigator), Inga Sif Olafsdottir, Katarina Nisser, Ulrike Spetz-Nyström, Gunilla Hägg and Gun-Marie Lund (Department of Medical Sciences: Respiratory Medicine and Allergology, Uppsala University, Uppsala, Sweden); Rain Jõgi (principal investigator), Hendrik Laja, Katrin Ulst, Vappu Zobel and Toomas-Julius Lill (Lung Clinic, Tartu University Hospital, Tartu, Estonia); Parvaiz A. Koul (principal investigator), Sajjad Malik, Nissar A. Hakim and Umar Hafiz Khan (Sher-i-Kashmir Institute of Medical Sciences, Srinagar, India); Rohini Chowgule (principal investigator), Vasant Shetye, Jonelle Raphael, Rosel Almeda, Mahesh Tawde, Rafiq Tadvi, Sunil Katkar, Milind Kadam, Rupesh Dhanawade and Umesh Ghurup (Indian Institute of Environmental Medicine, Mumbai, India); Imed Harrabi (principal investigator), Myriam Denguezli, Zouhair Tabka, Hager Daldoul, Zaki Boukheroufa, Firas Chouikha and Wahbi Belhaj Khalifa (Faculté de Médecine, Sousse, Tunisia); Luisito F. Idolor (principal investigator), Teresita S. de Guia, Norberto A. Francisco, Camilo C. Roa, Fernando G. Ayuyao, Cecil Z.Tady, Daniel T. Tan, Sylvia Banal-Yang, Vincent M. Balanag Jr., Maria Teresita N. Reyes and Renato B. Dantes (Lung Centre of the Philippines, Philippine General Hospital, Nampicuan and Talugtug, Philippines); Sundeep Salvi (principal investigator), Siddhi Hirve, Bill Brashier, Jyoti Londhe, Sapna Madas, Somnath Sambhudas, Bharat Chaidhary, Meera Tambe, Savita Pingale, Arati Umap, Archana Umap, Nitin Shelar, Sampada Devchakke, Sharda Chaudhary, Suvarna Bondre, Savita Walke, Ashleshsa Gawhane, Anil Sapkal, Rupali Argade and Vijay Gaikwad (Vadu HDSS, KEM Hospital Research Centre Pune, Chest Research Foundation, Pune India); Mohamed C. Benjelloun (principal investigator), Chakib Nejjari, Mohamed Elbiaze and Karima El Rhazi (Laboratoire d'Épidémiologie, Recherche Clinique et Santé Communautaire, Fes, Morroco); Daniel Obaseki 
(principal investigator), Gregory Erhabor, Olayemi Awopeju and Olufemi Adewole (Obafemi Awolowo University, Ile-Ife, Nigeria); Mohamed Al Ghobain (principal investigator), Hassan Alorainy (principal investigator), Esam Alhamad, Mohamed Al Hajjaj, Ayan Hashi, Rowena Dela, Rofel Fanuncio, Elizabeth Doloriel, Imelda Marciano, Lyla Safia (Saudi Thoracic Society, Riyadh, Saudi Arabia); Talant M. Sooronbaev (principal investigator), Bermet M. Estebesova, Meerim Akmatalieva, Saadat Usenbaeva, Jypara Kydyrova, Eliza Bostonova, Ulan Sheraliev, Nuridin Marajapov, Nurgul Toktogulova, Berik Emilov, Toktogul Azilova, Gulnara Beishekeeva, Nasyikat Dononbaeva and Aijamal Tabyshova (Pulmunology and Allergology Department, National Centre of Cardiology and Internal Medicine, Bishkek, Kyrgyzstan); Kevin Mortimer (principal investigator), Wezzie Nyapigoti, Ernest Mwangoka, Mayamiko Kambwili, Martha Chipeta, Gloria Banda, Suzgo Mkandawire and Justice Banda (The Malawi Liverpool Wellcome Trust, Blantyre, Malawi); Asma Elsony (principal investigator), Hana A. Elsadig, Nada Bakery Osman, Bandar Salah Noory, Monjda Awad Mohamed, Hasab Alrasoul Akasha Ahmed Osman, Namarig Moham ed Elhassan, Abdel Mu'is El Zain, Marwa Mohamed Mohamaden, Suhaiba Khalifa, Mahmoud Elhadi, Mohand Hassan and Dalia Abdelmonam (The Epidemiological Laboratory, Khartoum, Sudan); Hasan Hafizi (principal investigator), Anila Aliko, Donika Bardhi, Holta Tafa, Natasha Thanasi, Arian Mezini, Alma Teferici, Dafina Todri, Jolanda Nikolla and Rezarta Kazasi (Tirana University Hospital "Shefqet Ndroqi", Tirana, Albania); Hamid Hacene Cherkaski (principal investigator), Amira Bengrait, Tabarek Haddad, Ibtissem Zgaoula, Maamar Ghit, Abdelhamid Roubhia, Soumaya Boudra, Feryal Atoui, Randa Yakoubi, Rachid Benali, Abdelghani Bencheikh and Nadia Ait-Khaled (Faculté de Médecine Annaba, SEMEP Elhadjar, El Hadjar, Algeria); and Akramul Islam (principal investigator), Syed Masud Ahmed (co-principal investigator), Shayla Islam, Qazi Shafayetul Islam, Mesbah-Ul-Haque, Tridib Roy Chowdhury, Sukantha Kumar Chatterjee, Dulal Mia, Shyamal Chandra Das, Mizanur Rahman, Nazrul Islam, Shahaz Uddin, Nurul Islam, Luiza Khatun, Monira Parvin, Abdul Awal Khan and Maidul Islam (James P. Grant School of Public Health, BIGH/BRAC University, Dhaka, Bangladesh).

We want to thank the participants and field workers of this study for their time and cooperation. We also want to thank Anamika Jithoo (formerly of Imperial College, London, UK) and the BOLD Coordinating Centre (UK) members not included in the author list for their technical and scientific support.

\section{References}

1 World Health Organization (WHO). Global tuberculosis report 2013. Geneva, WHO, 2013.

2 Selwyn PA, Hartel D, Lewis VA, et al. A prospective study of the risk of tuberculosis among intravenous drug users with human immunodeficiency virus infection. N Engl J Med 1989; 320: 545-550.

3 Ando M, Mori A, Esaki H, et al. The effect of pulmonary rehabilitation in patients with post-tuberculosis lung disorder. Chest 2003; 123: 1988-1995.

4 Hicks A, Muthukumarasamy S, Maxwell D, et al. Chronic inactive pulmonary tuberculosis and treatment sequelae: chest radiographic features. Int J Tuberc Lung Dis 2014; 18: 128-133.

5 Miller TL, McNabb SJ, Hilsenrath P, et al. Personal and societal health quality lost to tuberculosis. PLoS One 2009; 4: e5080.

6 Vestbo J, Hurd SS, Agusti AG, et al. Global strategy for the diagnosis, management, and prevention of chronic obstructive pulmonary disease: GOLD executive summary. Am J Respir Crit Care Med 2013; 187: 347-365.

7 de Marco R, Accordini S, Marcon A, et al. Risk factors for chronic obstructive pulmonary disease in a European cohort of young adults. Am J Respir Crit Care Med 2011; 183: 891-897.

8 Lamprecht B, McBurnie MA, Vollmer WM, et al. COPD in never smokers: results from the population-based burden of obstructive lung disease study. Chest 2011; 139: 752-763.

9 Salvi SS, Barnes PJ. Chronic obstructive pulmonary disease in non-smokers. Lancet 2009; 374: 733-743.

10 Menezes AM, Hallal PC, Perez-Padilla R, et al. Tuberculosis and airflow obstruction: evidence from the PLATINO study in Latin America. Eur Respir J 2007; 30: 1180-1185.

11 Allwood BW, Myer L, Bateman ED. A systematic review of the association between pulmonary tuberculosis and the development of chronic airflow obstruction in adults. Respiration 2013; 86: 76-85.

12 Garvin A, Lundsgaard C, Van Slyke DD. Studies of lung volume: II. Tuberculous men. J Exp Med 1918; 27: 87-94.

13 Garvin A, Lundsgaard C, Van Slyke DD. Studies of lung volume: III. Tuberculous women. J Exp Med 1918; 27: $129-142$.

14 Hnizdo E, Singh T, Churchyard G. Chronic pulmonary function impairment caused by initial and recurrent pulmonary tuberculosis following treatment. Thorax 2000; 55: 32-38.

15 Pasipanodya JG, Miller TL, Vecino M, et al. Pulmonary impairment after tuberculosis. Chest 2007; 131: $1817-1824$.

16 Baig IM, Saeed W, Khalil KF. Post-tuberculous chronic obstructive pulmonary disease. J Coll Phys Surg Pak 2010; 20: $542-544$.

17 Ross J, Ehrlich RI, Hnizdo E, et al. Excess lung function decline in gold miners following pulmonary tuberculosis. Thorax 2010; 65: 1010-1015.

18 Ehrlich RI, Myers JE, te Water Naude JM, et al. Lung function loss in relation to silica dust exposure in South African gold miners. Occup Environ Med 2011; 68: 96-101.

19 Buist AS, Vollmer WM, Sullivan SD, et al. The Burden of Obstructive Lung Disease Initiative (BOLD): rationale and design. COPD 2005; 2: 277-283.

20 Miller MR, Crapo R, Hankinson J, et al. General considerations for lung function testing. Eur Respir J 2005; 26 : $153-161$.

21 Swanney MP, Ruppel G, Enright PL, et al. Using the lower limit of normal for the FEV1/FVC ratio reduces the misclassification of airway obstruction. Thorax 2008; 63: 1046-1051.

22 Hankinson JL, Odencrantz JR, Fedan KB. Spirometric reference values from a sample of the general U.S population. Am J Respir Crit Care Med 1999; 159: 179-187.

23 Lam KB, Jiang CQ, Jordan RE, et al. Prior TB, smoking, and airflow obstruction: a cross-sectional analysis of the Guangzhou Biobank Cohort Study. Chest 2010; 137: 593-600.

24 Pellegrino R, Viegi G, Brusasco V, et al. Interpretative strategies for lung function tests. Eur Respir J 2005; 26: 948-968.

25 Hwang YI, Kim JH, Lee CY, et al. The association between airflow obstruction and radiologic change by tuberculosis. J Thorac Dis 2014; 6: 471-476. 
26 Kim HY, Song KS, Goo JM, et al. Thoracic sequelae and complications of tuberculosis. Radiographics 2001; 21: 839-858.

27 Alber A, Howie SE, Wallace WA, et al. The role of macrophages in healing the wounded lung. Int J Exp Pathol 2012; 93: 243-251.

28 Holloway RA, Donnelly LE. Immunopathogenesis of chronic obstructive pulmonary disease. Curr Opin Pulm Med 2013; 19: 95-102.

29 Mosser DM, Edwards JP. Exploring the full spectrum of macrophage activation. Nat Rev Immunol 2008; 8: 958-969. 